\title{
FATO HISTÓRICO
}

\section{A FEBRE AMARELA NA REGIÃO DE RIBEIRÃO PRETO DURANTE A VIRADA DO SÉCULO XIX: IMPORTÂNCIA CIENTÍFICA E REPERCUSSÕES ECONÔMICAS}

\author{
Luiz Tadeu Moraes Figueiredo
}

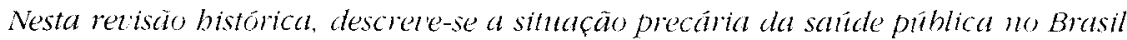
durante o século XIX devido is miltiplas epidemias de febre amarela. Descrere-se. também, os precáros conbecimentos que baviam, à época, sobre a enfermidade. Fazse am breite bistorico sobre a Regino de Ribeirao Preto situada no. Vordeste do Estado de Sào Palalo, sens deshratadores. imigrantes e fazendeiros de cafê pioneiros. inclaindo-se Luiz Pereira Barreto. Relatam-se as 3 epidemias de febre amarela ocomidas na cidade de São Simão, nos anos de 1896. 1898, 1902 e lama acomta em Riberräo Preto, 110 ano de1903. Mostra-se que as medidas de salade piblica lomadas para o controle dos surtos mostraram-se eficientes quando Emalio Ribas promone't, de forma pioneira, o combate ato mosquito transmisson; o Aedes ategypti. Descretem-se as experimentos efetrados por Emílio Ribas. com a participaça de Adolpho Lutze de Luiz Pereira Barreto, lisando confirmar a transmissão tetorial da febre amarela e afastar outras formas de contagio. Observa-se que as epidemias de febre amarela causaram prejuizo a desentolimento da Cidade de Sáo Simáo colaborando para a transferência do polo economico regional para Ribeiräo Preto. Ressalta-se a importancia das medidas de controle retorial e a dos experimentos sobre o mecanismo de transmissào da febre amarela. no desenuole imento da ciência médica e da salade pública no Brasil
\end{abstract}

Palaras-chates: Epidemias de febre amarela. Ribeiräo Preto. Säo Simaio. História da febre amarela

A febre amarela, gravíssimo flagelo e dizimadora de populaçóes, causou importantes efeitos, ainda pouco avaliados, sobre a economia, a sociedade, a ciência e o desenvolvimento do Brasil. Trata-se de uma doença tropical, que juntamente com a malária e outros males, inspirava horror e fazia com que os europeus tivessem receio do Brasil, considerado no século XIX, uma das áreas mais insalubres dos trópicos. Aos brasileiros poderosos do final daquele século, os grandes fazendeiros de café, assustava a dizimação de sua forca de trabalho bem como o abandono da emigração européia de trabalhadores, pelo temor da febre amarela ${ }^{3 *}$. Por outro lado, naquela época, florescia mundialmente e com influências no Brasil, o pensamento positivista.

\footnotetext{
Unidade Multidisciplinar de Pesquisa em Virologia Faculdade de Medicina de Ribeirão Preto, Universidade de São Paulo.

Endereço para Currespondência: Luiz Tadeu M. Figueiredo, Unidade Multidisciplinar de Pesquisa em Virologia/ FMRP/USP. 14049-900, Ribeirão Preto, SP, Brasil. Fax: (016) 633-1144

Recebido para publicação em 17/2/95.
}

Surgia a metodologia científica, onde se analisava os fenómenos biológicos de forma neutra, buscando a verdade. Quanto ao controle da febre amarela e ao de outras doenças tropicais, surgiu, naqquele momento, uma clara receptividade para a ciência, vendoa como uma esperanca para a soluçio destes males, em substituiça à situaço anterior, que era de um pessimismo próprio de país colonizado. E, realmente, no caso da febre amarela, ao invés de átribuí-la, simplesmente, de forma conformista a fenômenos climáticos e geográficos, buscou-se a fundo suas causas:.

A febre amarela. A febre amarela era também chamada de typho icteroide, typho amaril, mal de siào, vômito negro e febre das Antilhas. Ocorre no Brasil desde o século XVII, e é descrita no ano de 1694 por João Ferreira da Rosa em seu Tratado único da constituição pestilencial de Pernambuco"s. Também, o padre Antonio Vieira, citado por Almeida?, referia-se em 1692 a um pavoroso surto de febre amarela na Bahia, que deixou cheias as casas de moribundos; as igrejas, de cadáveres $e$ as ruas, de tumbas. Em 1849, inicia-se no Brasil uma pavorosa seqüencia de surtos de 
Fato Histórico. Figueiredo LTM. A febre amarela na região de Ribeirão Preto durante a virada do século XIX: importância cientifica e repercussōes econômicas. Revista da Sociedade Brasileira de Medicina Tropical 29:63-76, jan-fev, 1996

febre amarela, começando na Bahia e chegando, por mar, ao Rio de Janeiro, com os marinheiros doentes do navio dinamarquês Navarre. Em março de 1850, toda a cidade do Rio de Janeiro estava atacada pela febre amarela. Observou-se que a doença poupava os pretos e matava europeus, em muito maior freqüência que aos nativos, independentemente de idade, e com maior mortalidade entre os do sexo masculino ${ }^{37}$. Ocorriam, portanto, casos assintomáticos, casos incaracterísticos, como uma gripe, casos leves, moderados e graves ou malignos. Entre 1850 e 1902 , a febre amarela ocorreu anualmente no Rio de Janeiro, com exceçào de 1865, 1866 e 1867 , tendo causado o impressionante número de 58063 óbitos nesse período, numa cidade que, em 1850, contava com 166000 habitantes ${ }^{15}$.

Os conhecimentos sobre a febre amarela no século XIX. Na segunda metade do século XIX, ocasião que precedeu as epidemias na Região de Ribeirão Preto, a febre amarela tinha causa e mecanismo de transmissão desconhecidos. Discutia-se, inclusive, se era ou não contagiosa. Citada por Franco ${ }^{15}$, em maio de 1850, a Comissão Central de Saúde Pública do Rio de Janeiro, composta por grandes médicos da época, indicava indigestôes, a suspensão da transpiração, exposição à chuva, à umidade, ao sereno da noite e à insolação, e esta foi, sem dúvida, uma das mais fortes causas da sua produção entre nós. As fadigas do espírito, as contrariedades morais, as paixões violentas, o terror, etc, também concorrem muito para seu desenvolvimento. Torres Homem, um grande clínico da época, declarava, em 1875, que, para a febre amarela desenvolver-se em uma localidade qualquer, são necessárias certas condiçôes topográficas, telúricas e meteorológicas antevendo o conhecimento atual da necessidade de condições meteorológicas adequadas para a reprodução do mosquito Aedes aegypti, o vetor deste mal. Posteriormente, faria outras importantes observaçòes: para mim, a febre amarela nâo é contagiosa, o que, realmente, seria comprovado, como veremos a seguir ${ }^{15}$. Em 1885, Torres Homem, observando a ausência de epidemia de febre amarela em Petrópolis, Teresópolis e outras localidades de elevada altitude, apesar da presença de indivíduos com a doença, fugidos da epidemia do Rio de Janeiro, concluiu: o que prova isso, senão que o tifo americano (febre amarela) é exclusivamente infeccioso e não contagioso? Realmente, hoje sabe-se que em locais de altitude elevada não se aclimata bem o mosquito vetor, única forma de contágio, não ocorrendo, portanto, a transmissão ${ }^{18}$. Ainda, em 1885, Filogonio L. Utinguassú ${ }^{3}$, fisiologista da Faculdade de Medicina da Universidade do Brasil, propõe, em reunião da Academia Imperial de Medicina, que a febre amarela poderia ter como transmissor um mosquito que contaminava a água a ser bebida. Contudo, em 1885, não obteve boa receptividade a proposição do Dr. Utinguassú. Também, o médico cubano Carlos Finlay ${ }^{13}$, em 1881, publicou trabalho sugerindo precisamente que o mosquito Culex taeniatus, também conhecido como Stegomyia fasciata e, hoje, pelo nome de Aedes aegypti, seria o vetor transmissor da febre amarela. Mostrava resultados de suas pesquisas, os quais, infelizmente, eram insuficientes para uma confirmação absoluta. Em 1900, seguindo as idéias de Finlay, viria esta confirmação pela equipe médica do exército norte-americano em Cuba, chefiada por Walter Reed ${ }^{32}$. Em fevereiro de 1901, iniciaram-se trabalhos de saneamento e combate ao Aedes aegypti, que confirmaram, na prática, o mecanismo de transmissão vetorial, erradicando a febre amarela de Havana em 6 meses. As medidas de combate ao mosquito, tomadas pelo exército norte-americano ocupando a cidade, eram rigorosas e foram efetuadas sob o comando do sanitarista militar William Gorgas ${ }^{24}$.

Quanto à etiologia da febre amarela, acreditava-se, inclusive Finlay, na possibilidade de um protozoário ${ }^{38}$. como na malária e, no Brasil, o Dr. Domingos Freire isolou de cadáveres com febre amarela, uma bactéria, a qual denominou Micrococco ou Cryptococcus xanthogenico. O Micrococco xanthogenico foi estudado por múltiplos grupos de pesquisadores brasileiros e estrangeiros nos últimos anos do século XIX. Observou-se que esta bactéria produzia uma degenerescência gordurosa no fígado de coelhos e les_es hemorrágicas hepáticas em cães inoculados experimentalmente ${ }^{29}$. Foi produzida, inclusive, uma vacina com antígenos do Micrococco xanthogenico, a qual não se mostrou eficaz ${ }^{15}$. Outro microorganismo cotado como agente etiológico da febre amarela era o bacilo icteróide isolado por Giuseppe Sanarelli, de 
Fato Histórico. Figueiredo LTM. A febre amarela na região de Ribeirão Preto durante a virada do século XIX: importancia científica e repercussöes econômicas. Revista da Sociedade Brasileira de Medicina Tropical 29:63-76, jan-fet, 1996.

cadáveres e do sangue de indivíduos com febre amarela. Posteriormente, o Dr. João Batista de Lacerda, passou a divulgar esta etiologia, sugerindo que o bacilo icteróide viveria em simbiose com bolores que se apresentariam no solo das habitacoes e se espalhariam pelo ar de forma limitada, no interior ou proximidade destas habitaçoes ${ }^{20}$. A transmissão se faria por vebiculação esomatica dos bolores, isto é, através do transporte do germe no bolor em objetos e cousas que nào tiveram contato com excreçòes do doente" Também, o bacillo $X$ bavanensis foi mais uma bactéria isolada de cadáveres de amarelentos, em Cuba ${ }^{19}$. Uma nova idéia, com relação à etiologia da febre amarela, surge no começo do século XX, com o isolamento de um fermento em cadáveres e doentes amarelentos, a partir do figado, rins, sangue, estômago e vômitos ${ }^{22}$. A presença de células hialinas observadas no fígado por diversos patologistas e descritas por Klebs e Concilman como amebas ou protozoários seriam, na opiniāo de Lacerda, of fermento. Sabe-se que estas células hialinas, hoje conhecidas como corpos de Councilman, são hepatócitos necrosados. As pesquisas destes diversos autores tiveram méritos, apesar de não terem acertado com o causador da febre amarela. Porém, geraram debates acalorados e conflitos variados, que causaram uma certa dificuldade na aceitação da descoberta do verdadeiro agente etiológico da febre amarela. Esta, ocorreu em Cuba e foi feita por Walter Reed e sua comissão de médicos do exército americano (Caroll, Agramonte e Lazear), no ano de $1901^{32}$.

No século XIX e início do século XX, os experimentos por inoculação de seres humanos voluntários com microorganismos causadores de doenças graves, como é o caso da febre amarela, eram aceitos e até recomendados por grandes vultos da medicina. Louis Pasteur, em carta a D. Pedro II, no ano de 1884 , recomenda este tipo de experimento no caso da raiva, inclusive, insinuando que fossem utilizados prisioneiros condenados a morte ${ }^{i 5}$. A comissào de médicos do exército americano em Cuba, chefiada por Walter Reed, utilizou-se da exposição, ou mesmo da inoculação de seres humanos, para verificar se o microorganismo causador da febre amarela era transmitido através do sangue de enfermos, fômites, e/ou através de mosquito vetor contaminado. Participaram como voluntários pessoas que nunca entraram em contato com a febre amarela, soldados, emigrantes espanhóis e membros da própria equipe médica do exército, como o bacteriologista James Carrol e o médico Jesse Lazear, que se deixaram picar por mosquitos suspeitos de carregar o micróbio. Lazear adquiriu forma grave de febre amarela, vindo a falecer. Considerou-se, na época, que este foi o sacrifício máximo de um cientista, dando sua vida pela busca da verdade. Por fim, a comissão médica do exército norte-americano pôde concluir que o agente específico da febre amarela estaria presente no sangue, pelo menos nos 3 primeiros dias de doença e que poderia ser transmitido a outrás pessoas, embora neste sangue não se encontrasse qualquer microorganismo que crescesse nos meios de cultivo bacteriológicos. O microorganismo era inativado pelo calor $e$ transmissivel, mesmo quando passado por filtro de bactérias Berkefeld. Concluíram tratarse de um micróbio ultra-microscópico filtrável (vírus) $^{32}$. Hoje, sabe-se tratar-se do protótipo do gênero flavivirus da família Flaviviridae (favos-amarelo). Um microorganismo esférico, envelopado, de $60 \mathrm{~nm}$, possuidor de uma fita simples de RNA infectante com aproximadamente 10000 bases, contendo 10 genes codificadores das proteínas estruturais $\mathrm{E}, \mathrm{M}$ e $\mathrm{C}$ e das nãoestruturais NS1, NS2a, NS2b, NS3, NS4a, NS4b e NS5 ${ }^{+2}$.

A Região de Ribeirão Preto. A história da Região de Ribeirão Preto inicia-se por volta de 1680 , com a passagem, pelo Sertão do Rio Pardo, do bandeirante Bartolomeu Bueno da Silva, o Anhanguera (diabo velho), em sua viagem até os Guaiases (Goiás)". Por volta de 1725, seu filho, com o mesmo nome, em busca do ouro de Vila Boa, passou pela região ao seguir o caminho dos Guaiases ${ }^{27}$. Porém, a exploração do Sertão do Rio Pardo foi lenta. Ocorreu que, no início do século XVIII, após a guerra dos emboabas, os paulistas perderam suas minas de ouro. A Vila de São Paulo, e outras, como as do Vale do Paraíba, viveram anos de decadência, o que ainda foi agravado pela descoberta de um caminho novo para Vila Rica, evitando Taubaté e Guaratingüetá. Nesta ocasião, dificultaram-se as comunicações com o litoral e reduziram-se as incursões paulistas ao interior ${ }^{89}$. Por isso, o Sertão do Rio Pardo, situado na antiga trilha do Anhanguera, esteve quase abandonado durante todo século XVIII. Naqueles sertões, viviam, em pequena 
Fato Histórico. Figueiredo LTM. A febre amarela na região de Ribeirão Preto durante a virada do século XIX: importância cientifica e repercussôes econômicas. Revista da Sociedade Brasileira de Medicina Tropical 29:63-76, jan-fet, 1996.

quantidade, os bilreiros, como eram chamados pelos sertanistas os índios caiapós. Eles, provavelmente, habitavam numerosas tabas nas proximidades dos rios da Região de Ribeirão Preto, que eram muito piscosos. Estes índios foram sistematicamente exterminados ou afugentados ao longo do século XVII e XVIII, sob a alegação de que assaltavam viajantes paulistas e mineiros ${ }^{70}$. Contudo, terminava o ciclo das minas e voltavam-se os bandeirantes, progressivamente, para a ocupaçáo agro-pecuária, obtendo dos governadores das capitanias, facilmente, a concessão de sesmarias (3 léguas quadradas $)^{1011}$. Desta forma, houve um lento e pontilhado aparecimento de fazendas, seguindo o caminho dos Guaiases ${ }^{27}$. Já se iniciava o século XIX, quando chegaram à Regiào, bandeirantes, oriundos de Minas Gerais, buscando ouro e, também, a ocupaçào agro-pecuária das terras do Rio Pardo's. Esta ocupaça passou a ser incentivada após a transformação do Rio de Janeiro na Capital do Império Português, com a vinda da família real para o Brasil, em $1808^{\circ}$. Dentre os bandeirantes chegados nesta época, encontrase Simão da Silva Teixeira, fundador de São Simão, a primeira povoação da Região. Naquela ocasião, também, outras famílias mineiras pioneiras acorreram para ali, como os Junqueira e os Nogueira ${ }^{28}$.

Em 1833, a Região de Ribeirão Preto pertencia ao Distrito de São Simão (Figura 1) e era ocupada de forma esparsa por fazendas, dedicadas, principalmente, à criaçào de gado, cana-de-açúcar e cereais ${ }^{22} 2$ 2n. São Simão foi elevada a Vila em 1865 e, após 10 anos, possuía 3507 habitantes, sendo 777 escravos. Por volta de 1850, Ribeirão Preto era uma sesmaria do Padre Manoel Pompeu de Arruda, que a passou às màos do Capitão João Diniz. Junqueira" ${ }^{11}$ A Vila de São Sebastião de Ribeirão Preto desmembrou-se de São Simão em 1871 e, em 1875, possuía 5552 habitantes. sendo 857 escravos ${ }^{\text {th }}$. Na metade do século XIX esta era a regiào que mais possuía escravos na Província de São Paulo*.

Juridicamente, a Regiào pertenceu inicialmente a Casa Branca, sendo primeira comarca regional a de São Simão, criada em 1877. Ribeirão l'reto passou a comarca em 1892, separando-se de São Simão $0^{1028}$.

Alguns fazendeiros cafeicultores de Valença, Vassouras, Parati, Barra Mansa e Resende, como os irmáos Barreto que. chefiados por Luiz Pereira Barreto (Figura 2A), mudaram-se para ali. em 1876, comecaram a transformar a Região de Ribeirão Preto. Buscavam e ali encontraram as terras ideais para aquela cultura. Eles deixaram suas terras esgotadas na Serra do Mar e Vale do Paraíba e, a partir de Ribeirào Preto, transformaram o Nordeste do Estado de São Paulo num mar de café que avançou para o norte, chegando ao Rio Grande e fazendo da Região o maior empório cafeeiro do país ${ }^{27}$

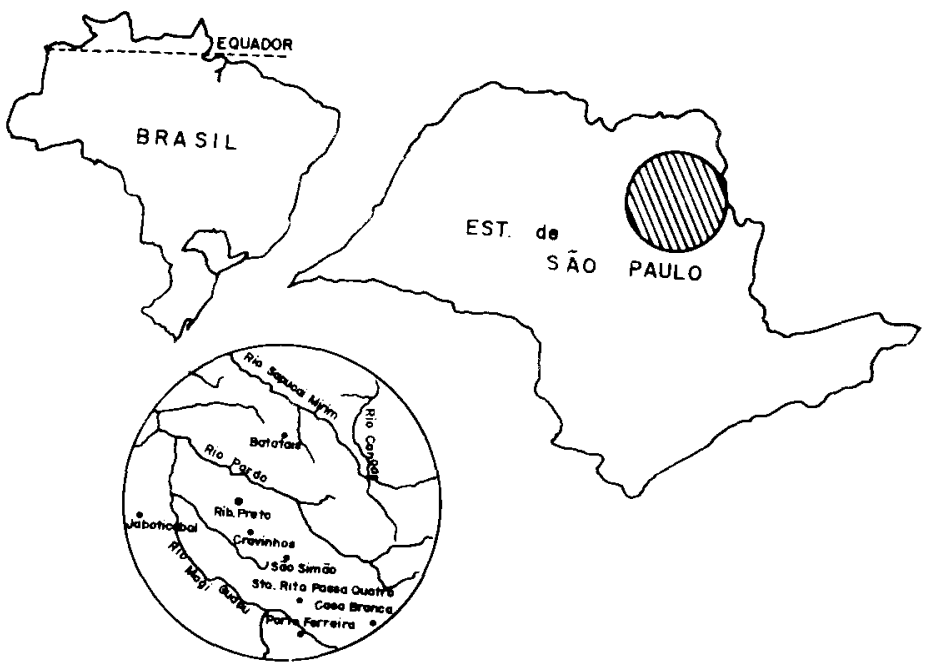

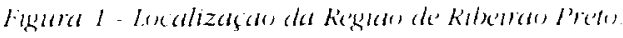


Fato Histórico. Figueiredo LTM. A febre amarela na região de Ribeirão Preto durante a virada do século XIX: importância cientifica e repercussóes econômicas. Revista da Sociedade Brasileira de Medicina Tropical 29:63-76, jan-fev, 1996.

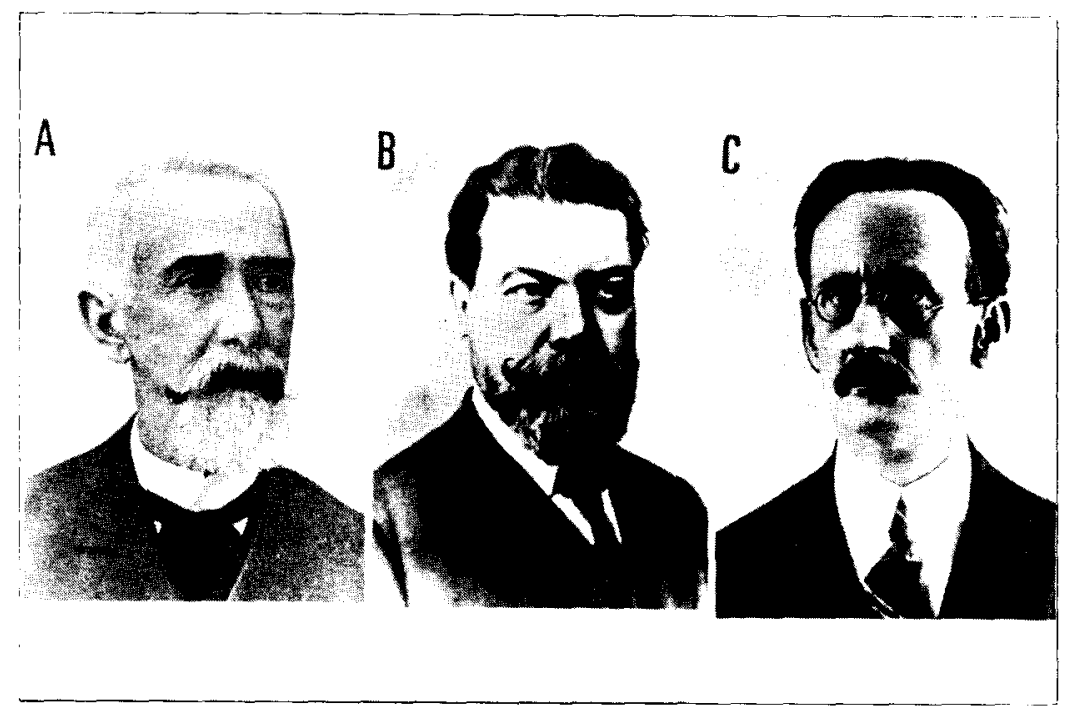

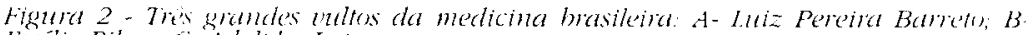
Emilio Ribas; C-Adolpho Lutz.

Para o trabalho na cafeicultura, que determinou este notável progresso, muito contribuiu o surgimento de uma preferência local pela mào de obra livre aos negros escravos. Houve enorme corrente imigratória de trabalhadores livres, principalmente de italianos, mas, também, de espanhóis, portugueses e japoneses. Entre 1889 e 1906, o Estado de São Paulo registrou a chegada de 1.039 .987 imigrantes $^{40}$.

Logo a estrada de ferro rasgou aqueles sertòes e foi de fundamental importância como fácil meio de transporte para o café até ao porto exportador de Santos. A Companhia Mogyana de Estradas de Ferro chegou a São Simão em 1882 e a Ribeirão Preto, distante aproximadamente $44 \mathrm{~km}$, em novembro de $1883^{122 x}$.

Pela estrada de ferro, que propiciou o progresso da Região de Ribeirão Preto, vieram alguns males. Destes, o mais terrivel foi a febre amarela, que veio juntar-se à malária, febre tifóide, tuberculose e varíola, dentre outras doenças já existentes na Regiâo ${ }^{28}$.

Em 1895, ocorria epidemia de febre amarela em Santos e a Secretaria de Negócios do Interior recomendava em São Simão uma ativa vigilância de todos os passageiros chegados, com desinfecção dos carros do trem e da bagagem ${ }^{3}$. Contudo, a epidemia avançou de forma inexorável nos rumos Norte e Oeste através das ferrovias paulista, Mogiana e Sorocabana, atacando São Caetano, Valinhos, Campinas, Rio Claro, Jaú, Pirassununga, Belém do Descalvado, Araraquara, Bebedouro, Barretos e Jaboticabal. Chegou a São Simão (Figura 3A) em janeiro de $1896^{6112+28}$.

A primeira epidemia de febre amarela em São Simão. Segundo o depoimento do exescravo Benedito Geraldo, o Nhô (Figura 3C), reproduzido por Oliveira e Nogueira (FP Oliveira, LA Nogueira: dados não publicados). o mal teria sido trazido a São Simão por famílias fluminenses e mineiras, que por ali chegaram fugidas da febre amarela. A epidemia inicia-se em 1896. Em fevereiro deste ano, o Dr. José Leme informava que muitos eram os doentes pobres e que estavam sem meios para se tratarem ${ }^{28}$. A Câmara Municipal pedia que providências fossem tomadas para a contencão do mal. Em $1^{\circ}$ de maio, o vereador Dr. Joào Fairbanks apresentava a seguinte indicação: Atendendo que neste Município se tem declarado febre de caráter epidêmico, proponho que seja o intendente autorizado a fazer toda e qualquer despesa com aquisição de material e pessoal necessário à desinfecção rigorosa, fornecimento de medicamento e alimentação próprias à população indigente, caixões mortuários, etc. Tomaram-se, na ocasião, medidas importantes, como a criação de um hospital de isolamento (lazareto) e a remoçào do cemitério local para sítio distando 
Fato Histórico. Figueiredo LTM. A febre amarela na região de Ribeirão Preto durante a virada do século XIX: importância cientifica e repercussöes econômicas. Revista da Sociedade Brasileira de Medicina Tropical 29:63-76, jant-fet, 1996.

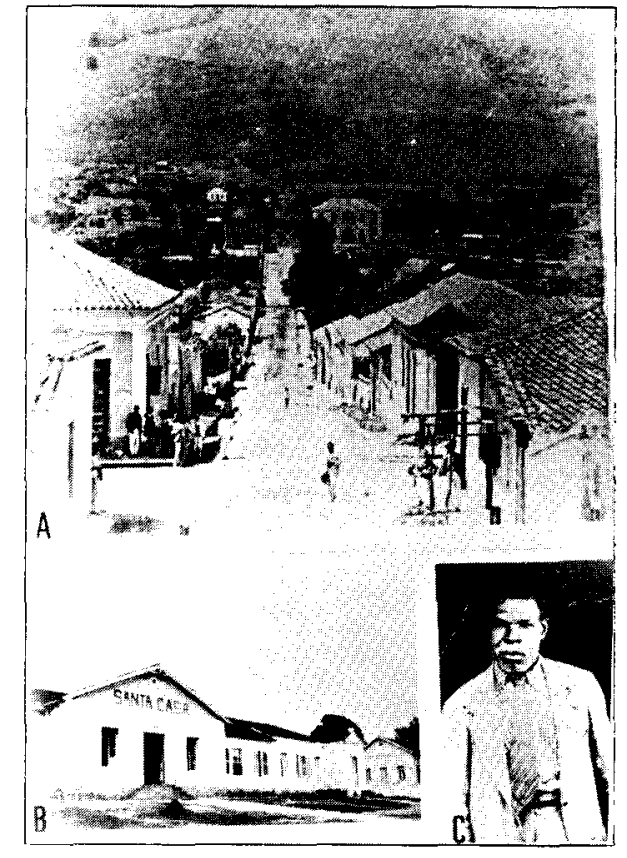

Figura 3 - Epidemias de febre amarela 'min Säo Simais: A-Aspecto da Cidade de sào Simäo no final do século XIX. vendose. ao fundo. uma plantaçà de café; $B$ Santa Casa de Säo Simuas, utilizada como hespital de isolamento. em fotografia lirada alguns anos apos as epidentias de Jebre aniarela: C-Benedito Geraldo (o ex-escravo Nhô) em fotografia obtida na década de 40. pelo menos $500 \mathrm{~m}$ do último arrabalde da cidade. Ao mesmo tempo, com a epidemia no auge, causando número cada vez maior de mortos, o governo estadual enviou sanitaristas a Sào Simão. Estranhamente, a Câmara Municipal local sentiu-se desprestigiada, afirmando que tinha serviço sanitário próprio, que a epidemia era de sua competência e que as medidas estaduais feriam sua autonomia ${ }^{28}$.

Desconhecendo-se o mecanismo de transmissão da febre amarela e buscando-se evitar transmissão a partir dos cadáveres, decidiu-se, a $1^{\circ}$ de julho de 1896 , mandar abrir uma vala ao redor do cemitério, enchendo-a de cal, encostar em toda a extensào lâminas de zinco, a fim de evitar infiltração, plantar eucalipto e colocar, em cada sepulcro dos cadáveres epidêmicos, 30 litros de cal, interditando-se o local. Um cemitério novo foi construído a $5 \mathrm{~km}$ da cidade, em pleno cerrado (hoje ali encontra-se a vila de Bento Quirino), porque acreditava-se que até o mau cheiro seria contagioso. Este cemitério passou a ser utilizado após a lotação total do antigo. Quanto ao lazareto, funcionou primeiramente em algumas salas ao lado do cemitério novo mas logo foi demolido por solicitação expressa da Diretoria de Hygiene do Estado, tendo se construído outro ${ }^{28}$ ( FP Oliveira, LA Nogueira: dados não publicados).
Atuaram no cuidado aos pacientes desta epidemia, o Comitato de Pública Assistência Cruz Vermelha e a Maçonaria. Descreve-se que familias inteiras, ou quase, morriam, às vezes, à mingua. Conta-se o caso de um jovem que, necessitando de assistência médica para si e seus familiares, morreu de febre amarela quando chegava ao lazareto para chamar o médico. Foi enterrado naquelas proximidades, onde se erigiu uma pequena capela. Diariamente, passava a carroça pelas ruas de São Simão, conduzida pelo ex-escravo Nhô, recolhendo os cadáveres e transportando-os para o cemitério novo. As vezes não era possível enterrar a todos no mesmo dia. Em 1945, desenterraram-se 5 crânios de uma cova comum, em local do cemitério que foi reservado ao sepultamento de amarelentos (FP Oliveira, LA Nogueira: dados não publicados).

A epidemia matou a quinta parte ou mais da população urbana de São Simão, que era de aproximadamente 4000 pessoas ${ }^{28}$. Outra enorme perda para a cidade foi a das pessoas que, apavoradas pela febre amarela, mudaramse para outras localidades. Após o arrefecimento da epidemia, no início de 1897 , apenas 2500 habitantes permaneciam em São Simão ${ }^{3}$. Escreveu o jornal O Estado de São Paulo, na edição de 8 de maio de 1897 , reproduzido por Oliveira ${ }^{28}$ : Graças a Deus e 
Fato Histónico. Figueiredo LTM. A febre amarela na região de Ribeirão Preto durante a tirada do sículo XIX: importancia cientifica e repercussóes econômicas. Revista da Sociedade Brasiletra de Medicina Tropical 29:63-76, jan-fet; 1996.

aos esforços dos inspetores sanitários, o estado sanitário desta cidade é muito animador. Alé este momento só existem 2 doentes, ambos recolhidos no hospital de isolamento. O aspecto da cidade é tristíssimo; ruas desertas, grande parte das casas abandonadas. Entretanto, se não fora a deserça dos habitantes de $S$. Simão, muito maior seria o número de vítimas. E conselho dos médicos e que convém ser reproduzido: ninguém deve, por encuanto, regressar a esta cidade, pois que viria atear novamente a fogueira, isto é, a epidemia recrudeceria e novos e acerbos sofrimentos viriam se ajuntar aos que têm amargurado o coração de todos os amigos e interessados pelo destino desta futurosa cidade. Conta-se que este conselho médico foi seguido de forma exagerada por muitas famílias que nunca mais vollaram. passando a residir em Ribeirâo Preto, Nhumirim, Icaturama (atual Sta. Rosa do Viterbo), Cravinhos e Cajuru. Algumas vezes, a fuga de São Simão era feita por harco pelo própro Riacho São Simào, que passa dentro da cidade, encontrando à frente o Rio Tamanduá e, finalmente, o Rio Pardo. Os fugitivos da febre amarela eram repelidos pelos moradores em muitos locais, quando sabiam que sua origem era São Simào. Eles temiam pegar a doença. Segundo o Cel. Leônidas Barreto, político da época, os maiores aglomerados de refugiados de Sào Simão teriam se localizado na fazenda dos Pereira Barreto, em Cravinhos e na Fazenda Palmeiras, em Ribeirão Preto. Ali existiria um cemitério abandonado, onde teriam sido enterrados amarelentos. Os numerosos refugiados eram alojados pelo comando sanitário de Ribeirão Preto, para quarentena, em barracòes, o que deu origem ao nome antigo de Barracão ao atual bairro ribeirão pretano do Ipiranga (FP Oliveira, LA Nogueira: dados não publicados).

A segunda epidemia de febre amarela em São Simão. Teve início em 1898. Houve nova correria, nova debandada e novos óbitos. Os enterramentos eram feitos somente no cemitério novo. Em 2 de maio de 1898, decidia a Câmara Municipal mudar sua sede para local distando $3 \mathrm{~km}$ da cidade até a extinção da epidemia. Este surto foi mais brando, causando apenas casos isolados. Não há registro oficial do número de mortos. Em 1899, o mal havia abrandado e São Simão voltava ao normal, porém, com sua população reduzida ${ }^{3}$ (FP Oliveira, LA Nogueira: dados nâo publicados).
A terceira epidemia de febre amarela em São Simào. Em 1902, quando Sào Simào comecava a esquecer-se das epidemias passadas, surge novamente a febre amarela de forma avassaladora. Os primeiros casos teriam sido observados ainda em outubro de 1901 mas se generalizaram no ano seguinte Novamente, a populaçao fugiu apavorada da cidade ${ }^{2-}$ (Livro do Tombo da Igreja Matriz de São Simão; FP Oliveira, lA Nogueira: dados não publicados).

Curiosamente, em 20 de junho de 1902. partindo de uma cidade vizinha, chega o primeiro pedido de providéncias ao servico sanitário estadual quanto a casos de febre amarela em sao Simáo. Fez-se imediatamente contato com são simáo, que respondeu as indagacoes referindo serem ótimas as condiçoes sanitárias da cidade. Não satisfeito com a resposta do intendente, o servico sanitário estachal enviou carta a um clínico local solicitando informaçòes. Recebeu resposta afirmativa- ali vinham ocorrendo casos de febre amarela. Referia o médico sobre a ocorrência de disputas científicas locais quanto a presença ou nào de febre amarela na ciclade, com interesses particulares envolvidos. E assim, sob diagnósticos estapafúrdios como febre remitente biliosa grave dos paises quentes, febre gastro-êntero-hepática, influenza complicada com impaludismo e entidade mórbida, enterraram-se muitos pacientes com febre amarela. Em 6 de julho, segue para São Simão o inspetor sanitário Dr. Carlos Meyer, que a pedido do municipio, vinha certificar-se das boas condiçōes sanitárias locais. O Dr Meyer, apesar de não encontrar nenhum caso de febre amarela, observou múltiplos exemplares de Aedes aegupti . Retornou a Sào Paulo, indicando para Sào simão uma campanha profilática de erradicação do mosquito vetor. Poucos dias depois, viria ao serviço sanitário estadual uma solicitaçào de providencias de parte do intendente municipal, já que haviam aparecido 4 ou 5 casos suspeitos. Manifestaram-se, então, os médicos locais, referindo que a epidemia teria se iniciado na praça central da localidade e, posteriormente, se espalhado, sendo que pelo menos 25 casos haviam ocorrido, a metade fatais $s^{\text {b. }}$.

Em 1902, já era conhecido o mecanismo de transmissão da febre amarela, bem como as formas de debelá-la e, pela primeira vez durante uma epidemia, aplicou-se no Brasil, 
Fato Histórico. Figueiredo LTM. A febre amarela na região de Ribeirào Preto durante a virada do século XIX: importancia científica e repercussôes econômicas. Revista da Sociedade Brasileira de Medicina Tropical 29:63-76, jan-fer, 1996.

em São Simão, as medidas de controle vetorial. Para isto, Emílio Ribas (Figura 2B), diretor do serviço sanitário, enviou ao local, em agosto de 1902, uma comissão de inspetores sob o comando do Dr. Francisco Luiz Viana ${ }^{3-4}$.

Emílio Ribas relacionava em 7 itens as medidas a serem tomadas para controle da febre amarela ${ }^{33}$ :

1. Evitar as águas estagnadas nas habitações e seus arredores;

2. Quando não for possivel evitar as coleções de água, derramar querosene sobre estas coleçōes;

3. Proteger os enfermos por meio de cortinados;

4. Extinguir por todos os meios os mosquitos encontrados nos domicílios;

5. Proteger as habitações dos mosquitos com telas em portas e janelas;

6. Fechar e proibir a entrada de pessoas na casa de enfermos antes do tratamento local com inseticidas;

7. Proteger dos mosquitos, nos hospitais, os enfermos com febre amarela

A comissão sanitária enfrentou enormes dificuldades devido às condiçôes locais, que foram descritas por Emílio Ribas de forma pouco lisonjeira. A cidade (Figura 3A), localizada a 635 metros acima do nível do mar, possuía um clima dos mais quentes do estado. Era atravessada, em toda a sua extensão, por um córrego cheio de curvas e com pouca correnteza, que formava espraiados, alagadiços e que era represado em alguns pontos. Havia, ainda, cisternas mal feitas e pouco limpas. Segundo Emílio Ribas, São Simão tinha a atividade febril característica daquela região cafeeira. Com constituiçào étnica completamente heterogênea, a população, em parte recém-chegada, vivia em situação provisória. A cidade possuía 530 prédios, 90\% mal construídos, sem forro ou assoalho, não observando preceitos de higiene ou conforto. Era desprovida de esgotos, sendo o serviço feito em fossas fixas ${ }^{34}$.

A comissão sanitária buscou entendimento, primeiramente, com os clínicos locais. Contudo, as idéias novas quanto ao mecanismo de transmissão da febre amarela nào foram unanimemente aceitas pelos médicos, o que dificultou a execução das medidas previstas. Instruiu-se a população quanto à necessidade de sua cooperação no combate ao mosquito rajado (Aedes aegypti), destruindo as larvas em seus criadouros. Buscou-se convencer as pessoas da necessidade de procurar assistência médica, ao surgirem os primeros sintomas de febre amarela e de que estes casos deveriam ser internados, o que não era bem aceito pelos leigos. Também, foi difícil convencer os médicos locais quanto à necessidade de hospitalizaçào dos amarelentos. Devido a estas resistências, buscando não utilizar métodos violentos, tolerou-se o isolamento domiciliar, sendo que a primeira internação só veio a ocorrer em dezembro. Os enfermos ficavam em casa, sob cortinados, visando evitar que fossem picados por mosquitos e eram vigiados por membros da comissão ${ }^{3+}$. Na ocasião, o hospital de isolamento começou a funcionar no atual prédio da Santa Casa local (Figura 3B) ${ }^{2 s}$. Um dos membros da comissão sanitária, o Dr. Coutinho, faleceu em São Simão vitimado pela febre ${ }^{2 s}$.

Em agosto de 1902, Emílio Ribas veio a São Simão acompanhado de outros médicos e hospedou-se no antigo Hotel dos Viajantes. Também, o cientista teria solicitado a contribuição de moradores ao serviço da equipe médica, tendo obtido apenas um pequeno número de voluntários, estando entre eles o ex-escravo Nhô. Explicou-lhes que tinha interesse em conhecer a forma pela qual a doença se propagava na comunidade (FP Oliveira, LA Nogueira: dados não publicados).

A Comissão pôde observar o agravamento do surto, em 1902, com casos surgindo na seguinte seqüência: 12/08 - 1 caso fatal; 4/09 1 caso; $22 / 10$ - 1 caso; $15 / 11$ - 4 casos; $16 / 11$ 5 casos; a partir desta data observou-se aparecimento crescente de doentes até atingir o máximo em 28/12 com 11 casos. A população encontrava-se apavorada, abandonava a cidade, inclusive, abandonou-a até a administração municipal e foi possível à comissão impor suas regras, incluindo-se a de internação obrigatória. Buscando-se evitar a disseminação da febre amarela a partir de pacientes, instalaram-se telas de arame em todas as janelas e portas do hospital de isolamento, após um rigoroso expurgo de todos os seus cômodos 35 .

Diz-se que Emílio Ribas buscava, de todas as formas, mostrar aos médicos locais e à população que o contágio da febre amarela não se dava por contato, inclusive, conta-se que durante uma visita ao hospital de 
Fato Histónico. Figueiredo LTM. A febre amarela na regiâo de Ribeirão Preto durante a virada do século XIX: importância cientifica e repercussojes econômicas. Relista da Sociedade Brasileira de Medicina Tropical 29:63-76, jan-fet: 1996.

isolamento, o eminente sanitarista colocou o dedo em secreções de um amarelento recémfalecido e em seguida inseriu o dedo em sua propria hoca (FP Oliveira, LA Nogueira: dados nào publicados).

Criou-se uma casa de abrigo para os familiares dos amarelentos, que tinham sua residência interditada, às vezes, por mais de 2 dias. A medida visava a prevenção e a remoçào de futuros casos. As casas interditadas tinham suas aberturas calafetadas e eram tratadas pela queima de píretro na proporção de $13 \mathrm{~g} / \mathrm{m}^{3}$ nas casas forradas $e$, enxofre. na proporção de $60 \mathrm{~g} / \mathrm{m}^{3}$ nas não forradas, que eram a maioria. Moradias proximas às dos enfermos tambem eram expurgadas. Utilizaram-se, ainda, pulverizaçoes de creolina e de sublimado nas casas em que o aparecimento de doentes era reincidente. Contudo, as casas possuiam muitas frestas por onde fugiam os mosquitos, dificultando sua destruicão durante os tratamentos domiciliares. Também, todas as peças de roupa, bem como colchòes dos enfermos, eram esterilizados em estufa de Geneste \& Herscher. Estas últimas medidas eram tradicionais e buscavam prevenir a transmissão por contato o que, segundo os trabalhos feitos em Cuha, não ocorria na febre amarela ${ }^{3 .}$

Com a colaboração de trabalhadores municipais, canalizou-se o córrego São Simào, fez-se a drenagem das margens e promoveu-se a eliminaçao de criadouros de mosquitos, limpando-se os capinzais do perímetro urbano, removendo-se latas vazias, cacos de garrafas e outros recipientes que pudessem colecionar água. Refere Emílio Ribas que o clima ajudou no controle da epidemia, porque ocorreram períodos de baixas temperaturas que reduziram a velocidade de multiplicaçào do mosquito.".

A cidade, desta vez, ficou quase completamente abandonada e muitas foram as vítimas. O mal só foi exterminado em maio de 1903, quando conseguiu-se reduzir a população de mosquitos por meio das medidas sanitárias, embora não existam citaços específicas sobre a aferição de índices de infestação vetorial. A população começou a retornar aos lares em junho ${ }^{28}$.

Em 1904, veio para São Simão o médico sanitarista Rego Barros, que tomou as providencias complementares para manter saneada a cidade. Desde então, não ocorreram mais casos de febre amarela na localidade ${ }^{2 R}$.
Experimentos sobre a transmissão da febre amarela. Motivaram estes experimentos a obstinação de grupos de médicos brasileiros em não aceitarem a transmissibilidade da febre amarela pelo mosquito, mesmo após a comprovação pelos experimentos da comissão do exercito norte-americano em Cuba, corroborada pelas atividades saneadoras de Emílio Ribas em Sorocaba e Sào Simão. Apontavam, estes médicos, erros nos estudos feitos em Cuba, aventando a possibilidade de outros mecanismos de infecçào. Atribuíam a erradicaçào da febre amarela em Havana às medidas de desinfecçào e, principalmente, às obras sanitárias executadas pelos norleamericanos, independente da exterminaçào dos mosquitos ${ }^{35}$.

Os experimentos foram idealizados por Emílio Ribas, com rigor científico, repetindo de forma distinta o que Walter Reed havia feito em Cuba. Como primeira medida, noneou uma comissão médica de alto nível, experiente no diagnóstico da febre amarela e isenta, para dirigir e avaliar os resultados dos experimentos. Esta era composta pelos seguintes médicos: Luiz Pereira Barreto, Adriano de Barros e AG da Silva Rodrigues"s.

O trabalho foi iniciado no final de 1902. obtendo-se larvas de Aedes aegupti na cidade de Itu, tida como possuidora de água com excelente qualidade e onde ainda não havia ocorrido a febre amarela. Os mosquitos foram enviados a São Simâo para que os fizessem picar indivíduos com febre amarela. Posteriormente, os mosquitos foram levados à Cidade de São Paulo, onde não havia febre amarela. Dezesseis dias depois, em janeiro de 1903, no hospital de isolamento (hoje Hospital Emílio Ribas), picaram 6 pessoas. $O$ próprio Emílio Ribas, Adolpho Lutz (Figura 2C) e Oscar Moreira, deixaram-se picar pelos mosquitos que haviam previamente sugado doentes graves de febre amarela. Contudo, não manifestaram sintomas da moléstia. O resultado negativo foi atribuído a uma imunidade prévia, já que Ribas, Lutz e Moreira haviam tido contato prévio com epidemias da doença. As outras pessoas que foram picadas viviam em localidades onde nunca aparecera febre amarela e jamais haviam entrado em contato com a enfermidade: Domingos Vaz, André Ramos e o italiano Januário Fiori. Todos, avaliados pela comissão médica, apresentaram sintomas de febre amarela. Os 2 
Fato Histórico. Figueiredo LTM. A febre amarela na região de Ribeirão Preto durante a virada do século XIX: importância cientifica e repercussóes económicas. Revista da Sociedade Brasileira de Medicina Tropical 29:63-76, jan-fel, 1996.

primeiros tiveram formas benignas da infecção e Fiori apresentou quadro mais grave. Sua doença apareceu 3 dias após a picada, manifestando-se com febre elevada, hemorragias, albuminúria e ictericia. Contudo, o paciente recuperou-se $\mathrm{e}^{3,35}$.

Os experimentos mostravam claramente a transmissão vetorial da febre amarela, mas era preciso provar que a doença não era transmitida por vestes sujas e excretas dos enfermos, como preconizavam os contagionistas ${ }^{35}$. Inicioul-se, então, uma nova série de experimentos.

No Pavilhão II do Hospital de Isolamento de Sâo Paulo, preparou-se um quarto isolado do exterior por meio de tela fina de arame colocada entre a veneziana e a vidraça lacrando-se a veneziana e recobrindo-se a vidraça com um pano vermelho para reduzir ao mínimo a entrada de luz. O quarto continha uma estufa a gás que deveria manter a temperatura ambiente por volta de $20^{\circ} \mathrm{C}$ e, no dia anterior ao experimento, foi expurgado com gás sulfuroso. Às 21 horas e 30 minutos do dia 20 de abril de 1903 , na presença da comissão médica, de Emílio Ribas e outros doutores, confinou-se, neste quarto, o italiano Giuseppe Malagutti, o qual vestiu as roupas de amarelentos mortos e cuja cama foi preparada com fronhas e lençóis sujos de sangue e de vômitos negros de pacientes falecidos em São José do Rio Pardo, São Simão e Taubaté. Nos dias seguintes, outros italianos, Angelo Paroletti e Giovanni Siniscalchi, juntaram-se ao primeiro. Os 3 haviam chegado há menos de 1 ano ao Brasil e não haviam tido contato com a febre amarela. Durante a noite verificavam-se diversas vezes se vestiam as roupas e dormiam nos leitos sujos. No dia 27 , espalharam-se sobre suas vestimentas e sobre o assoalho, sangue vomitado, fezes e urina de doentes de Casa Branca e de Ribeirão Preto, que haviam sido trazidos em frascos fechados. Adolpho Lutz, em visita ao quarto, constatou que embora o ar se achasse impregnado, viciado e fétido, os 3 confinados encontravam-se saudáveis e bem humorados. Interrompeu-se o experimento no dia $1^{\circ}$ de maio quando a comissão médica informou que todos encontravam-se bem. Permaneceram no hospital, em observação, por mais 10 dias e tiveram alta em perfeita saúde ${ }^{3+35}$.

Concluiu a comissão médica, em 15 de junho de 1903, que, com base nos experimentos, é completamente infundada a crença relacionada à transmissâo da febre amarela por fomites. Recomenda, portanto, o abandono das medidas sanitárias baseadas na contagiosidade do mal. Propôs, como sugestão, que cada doente poderia permanecer em casa, protegido contra as picadas do mosquito por um simples cortinado, evitando-se as remoçôes violentas e as ocultaçôes, por familiares, de seus entes queridos. Isto facilitaria as notificaçôes de casos, levando ao combate mais efetivo ao mosquito infectado, com melhores resultados em termos do controle epidêmico. Também, deveria ser simplificado o expurgo das moradias, buscando apenas o extermínio do vetor".

A febre amarela na Cidade de Ribeirão Preto. O surto de febre amarela em Ribeirão Preto eclodiu no começo de1903, quando a cidade possuia aproximadamente 15000 habitantes. A 31 de janeiro de 1903, o sanitarista Dr. Francisco Viana dirige-se àquela cidade planejando pôr em prática os princípios sanitários de combate à doença já experimentados em São Simão ${ }^{15}$.

Em Ribeirão Preto houve apoio ao serviço de saneamento por parte das autoridades municipais e mobilizou-se, durante 1 mês, tempo necessário para um ciclo preliminar de limpeza da cidade, 200 homens, com 30 carroças. Foram removidas aproximadamente 4000 carroças de lixo, constituído de latas, garrafas e outros materiais próprios para coleção de água, servindo como criadouros do Aedes aegypti. Tomaram-se medidas apenas limitadas ao combate ao vetor, abandonandose a esterilização de roupas e o uso de desinfetantes nas casas, procedimentos que haviam sido feitos em São Simão ${ }^{35}$.

Foram notificados 810 casos de febre amarela. Na Santa Casa de Misericórdia, fundada em 1902, internaram-se vários casos de febre amarela e o Dr. Luiz Pereira Barreto teria ali atendido estes pacientes" ${ }^{11}$ Em 11 de julho de 1903, a epidemia foi considerada debelada, reiniciando-se as aulas nas escolas públicas locais (Câmara Municipal de Ribeirão Preto, atas das reuniões de 1903). Em Ribeirão Preto, também, ocorreu fuga da população durante a epidemia. A cidade ficou deserta e houve queixas de proprietários que, ao retornarem, encontraram suas residencias saqueadas $^{31}$.

Emílio Ribas, em 1909, ao descrever a erradicação da febre amarela no Estado de São 
Fato Histórico. Figueiredo LTM. A febre amarela na região de Ribeirão Preto durante a virada do século XIX: importância cientifica e repercussôes econômicas. Revista da Sociedade Brasileira de Medicina Tropical 29:63-76, jan-fev, 1996.

Paulo, na Society of Tropical Medicine and Hygiene, em Londres ${ }^{35}$, refere-se ao surto de Ribeirão Preto como aquele em que, definitivamente, se pode provar que o combate ao mosquito é a medida mais importante para se debelar a doença (Figura 4). Justifica sua afirmação com o fato de não haverem ocorrido mais casos de febre amarela na cidade, apesar de possuir uma população enorme de emigrantes estrangeiros, principalmente italianos, completamente susceptíveis à febre amarela e, também, por ali ter sido praticada, exclusivamente, a exterminação dos mosquitos pela destruição de seus viveiros.
Considerações finais. Os experimentos de Emílio Ribas com seres humanos justificaramse pela notável importância prática que tinha, na época, a confirmação definitiva do mecanismo de transmissão da febre amarela. Prova do mérito e do rigor científico destes experimentos foi a participação nos mesmos de um dos maiores cientistas brasileiros, o Dr Adolpho Lutz que, inclusive, se deixou infectar pela febre amarela. As conclusōes relativas aos experimentos de Ribas foram corroboradas no mesmo ano de 1903, pelos resultados dos estudos de uma missão de cientistas franceses, os doutores Marchoux, Salimbeni e Simond,

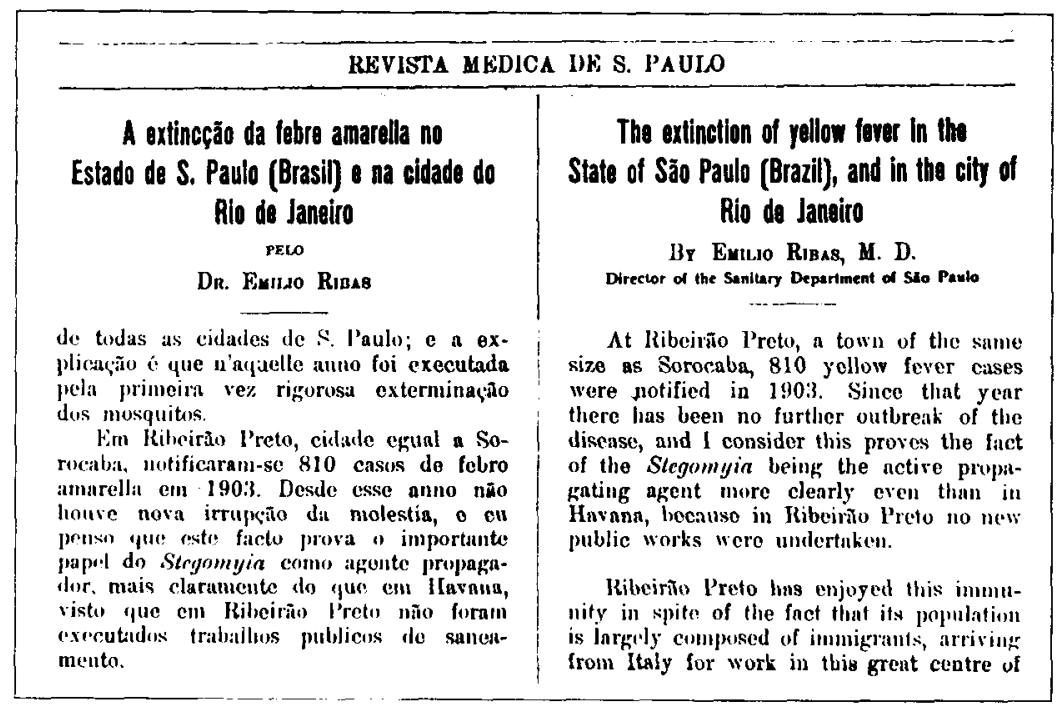

Figura 4 - Texto da publicacau de Emilio Ribas na Rentsta Médica de S. Panlo em $1909^{t 5}$, referindo-se ao surto de Ribeiräo Preto como aquele e'm que, definitivamente, se pode provar que o combate ao mosquito é a medida mais impontante para se debelar a febre amarela.

que entre 1901 e 1903, estudaram a febre amarela no Rio de Janeiro 25 .

Emílio Ribas, diretor do serviço sanitário estadual, teve atitude exemplar durante o periodo de transição entre as idéias antigas, místicas e, na maioria falsas, sobre a febre amarela e os conhecimentos modernos, obtidos a partir do método científico. Baseando-se exclusivamente em dados comprovados cientificamente, evitou querelas com outros médicos que tinham opiniões distintas e, por fim, comprovou suas idéias por meio dos procedimentos sanitários vitoriosos no controle dos surtos de febre amarela e de seus experimentos confirmadores do mecanismo de transmissão da doença.

Segundo Emílio Ribas, citado por Vieira ${ }^{41}$, a febre amarela no Estado de São Paulo, incluindo-se a Região de Ribeirão Preto, teria dizimado pelo menos 30000 pessoas, entre 1888 e 1903. Neste ano, ela foi erradicada em conseqüencia dos trabalhos por ele dirigidos ${ }^{11}$.

As epidemias da Região de Ribeirão Preto ocorreram no importante momento em que, 
Fato Histórico. Figueiredo LTM. A febre amarela na região de Ribeirão Preto durante a virada do século XIX: importância científica e repercussões econômicas. Revista da Sociedade Brasileira de Medicina Tropical 29:63-76, jan-fev, 1996.

com o descobrimento dos agentes etiológicos e do mecanismo de transmissão de doenças, aqui incluindo-se a febre amarela, iniciava-se a medicina científica no Brasil. Estas epidemias propiciaram, pela primeira vez, a tomada de medidas sanitárias eficazes no combate à doença, que levaram ao controle da mesma na Região e forneceram subsídios fundamentais a campanhas maiores, como foi a de Oswaldo Cruz no Rio de Janeiro ${ }^{35}$. Também, é importante salientar que nesta década (19011910), iniciada pelo controle das epidemias da Região de Ribeirão Preto, erradicou-se, quase completamente, a febre amarela urbana do país $s^{35}$

As epidemias de febre amarela na Região de Ribeirão Preto representaram grave transtorno a uma regiâo que vinha se desenvolvendo a pleno vapor, por conta da cafeicultura em expansão. Como conseqüência da febre amarela, é provavel que tenha havido um grave prejuizo ao desenvolvimento e ao futuro da Cidade de São Simão, que teria perdido parte de sua população em virtude das fugas, mortes e, após as 3 epidemias, teria passado a ser vista pelos potenciais imigrantes como local insalubre. Talvez tal fato fosse pressentido por autoridades locais que, na ocasião das epidemias, divulgavam com dificuldade informações sobre o que ali ocorria. Anos mais tarde, mesmo na cidade, mantinha-se um temor supersticioso pela febre amarela, o qual fez com que os túmulos de amarelentos, inclusive de indigentes, permanecessem intocados nos cemitérios locais, por quase 50 anos (Nogueira LAhistoriador de São Simão: informação pessoal, 1994). Pode-se imaginar que São Simão seria hoje uma cidade maior e de maior importância econômica, não fossem as 3 epidemias. Provavelmente, a febre amarela influiu no deslocamento do polo de desenvolvimento econômico regional para Ribeirão Preto.

Luiz Pereira Barreto tinha enorme confiança na ciência para a solução do problema amarílico e afirmava: devemos reunir todos os nossos esforços para descobrir uma resposta para o problema . Esta idéia era de dificil entendimento num país onde, mesmo os intelectuais, pouco se interessavam pela ciência ou seu progresso e onde a medicina experimental era feita apenas em escala pequena, no Rio de Janeiro e Bahia. A comprovação, em São Paulo, do mecanismo de transmissão da febre amarela, baseada em informaçôes obtidas cientificamente, representou um notável estímulo para o desenvolvimento das ciências e da pesquisa. $\mathrm{Na}$ verdade, os fatos aqui relatados tiveram importante influência para o progresso da medicina e da saúde pública no Brasil ${ }^{7121+193038}$.

\section{SUMMARY}

Yellow feter in the Region of Ribeirao Preto at the tum of XIX century: scientific importance and economic repercussion. This bistorical review describes the bad situation of public bealth in Brazil during the XIX Century cansed by multiple yellow fever outbreaks. The knowledge regarding to yellow fever at that time is also described. A short bistory is presented of the development of the Region of Ribeirao Preto, located in the Northeast of Sao Paulo State, Brazil, emphasising the actuation of immigrants and pioneer coffee farmers like Luiz Pereira Barreto. Yellow fever outbreaks occurred in the City of Sao Simao in 1896, 1898, and 1902 are described as well as an outbreak in the City of Ribeirao Preto occurring in 1903. It is shown that yellow fever outbreaks were stopped in the 2 cities by Emilio Ribas who led the fight against the transmitting mosquito Aedes aegypti . Emilio Ribas, belped by Adolpho Lutz and Luiz Pereira Barreto, promoted scientific experiments in order to confirm the vectorial transmission of yellow feter and to annul the supposed importance of otber kinds of contagion. The yellow fever outbreaks caused damage to the development of Sao Simao and influenced the transference of the economic pole of the region to the City of Ribeirao Preto. The tector control work done during yellow fever outbreaks and the scientific experiments on the transmission of yellow feter were important for the development of medical science and fpublic health in Brazil.

Key-words: Yellow fever outbreaks. Ribeirão Preto. São Simão. History of yellow ferer.

\section{AGRADECIMENTOS}

A José Carlos Batiston, Aramis Augusto Pinto, Maria Cristina Rossini Pinto, José Júlio Pasti Filho, Luiz Antonio Nogueira e Fernando Túbero pelo auxílio nas pesquisas. A Diléo Salviano Reis pelo desenho do mapa, a Ulisses Meneghelli pelas sugestões quanto à redação do manuscrito e à Rita Helena Carlucci pela revisão do texto. 
Fato Histórico. Figueiredo LTM. A febre amarela na região de Ribeirão Preto durante a virada do século XIX: importância científica e repercussôes econômicas. Revista da Sociedade Brasileira de Medicina Tropical 29:63-76, jan-fev, 1996.

\section{REFERÊNCIAS BIBLIOGRÁFICAS}

1. Abreu JC. Antecedentes indígenas. In: Capítulos de história colonial (1500-1800) e os caminhos antigos e o povoamento de Brasil. $5^{a}$ edição, Universidade de Brasília, Brasília, p.31-41, 1963.

2. Almeida G. Febre Amarella. In: Moléstias infecciosas e parasitárias. $6^{a}$ edição, Freitas Bastos, Rio de Janeiro, p. 363-410, 1940.

3. Bacellar RC. Brazil's contribution to tropical medicine and malaria-personalities and institutions. Olímpica, Rio de Janeiro, 1963.

4. Barbosa P. Pequena historia da febre amarella no Brazil. Archivos de Hygiene 1:5-35, 1929.

5. Barreto LP. Contribuição para o estudo da epidemiologia da febre amarela em S. Paulo. O Estado de São Paulo, 3 de abril de 1900.

6. Barreto LP, Rodrigues AGS, Barros A. Febre amarella (Experiências realizadas no Hospital de isolamento de São Paulo para verificação do contágio da febre amarella por intermédio das roupas ou dejeções dos doentes desta moléstia). O Brazil-Medico 17:306-308, 1903.

7. Barros RSM. A evolução do pensamento de Pereira Barreto. Grijalbo, São Paulo, 1967.

8. Bonato J. Usineiro financia livro sobre Ribeirão Preto. Folha de São Paulo (folha nordeste) 25/12/94.

9. Calmon P. Emboabas e paulistas. In: Calmon P (ed.) História do Brasil. José Olympio, Rio de Janeiro, vol. 3, p. 959-975, 1959.

10. Capalbo CR. A história de Jaboticabal 1828-1978. Jaboticabal, 1978.

11. Conte MVB, Santo AE. Cem anos de Ribeirão Preto. Publicação dedicada ao $1^{\circ}$ centenário da Cidade de Ribeirão Preto- E. São Paulo. Conte, São Paulo, 1956.

12. Ferreira JP. Ribeirão Preto-SP. In: Enciclopédia dos Municípios Brasileiros. Rio de Janeiro, IBGE, 1957. p.287-289.

13.Finlay CJ. O mosquito hipoteticamente considerado como agente de transmissão da febre amarela. In: Exposito CR. Extracto de Carlos J. Finlay - obras completas. Academia de Ciências, La Habana, 1965. p.110.

14. Fontoura C. Evocação de Pereira Barreto. Revista Brasileira de Medicina 15.

15. Franco O. História da febre amarela no Brasil. Ministério da Saúde, Rio de Janeiro, 1976.

16. Grave J, Netto C (eds.). Dicionario Lello Universal. Lello \& Irmão, O Pôrto, 1935.
17. Grolier Computer Multimidia Enciclopedy. Grolier Electronic Publishing, Danbury (USA), 1993.

18. Homem JVT. Estudo clínico sobre as febres do Rio de Janeiro. $2 \mathrm{a}$ ed., Lopes do Couto \& Cia, Rio de Janeiro, 1886.

19. Lacaz CS. Vultos da Medicina Brasileira. Helicon, São Paulo, 1963. p.2.

20. Lacerda JB. Provas e argumentos em favor da localisação intra-domiciliar da febre amarella. $O$ Brazil-Medico 13:339-342,1899.

21. Lacerda JB. Factos concordantes e provas indiretas da interferência dos bolores na propagação da febre amarella. $\mathrm{O}$ Brazil-Medico 13:212-214,1899.

22. Lacerda JB. Novos estudos sobre a febre amarela. O Brazil-Medico 16:109-110,1902.

23. Leonard J. William Gorgas, soldado de la salud pública. Boletin de la Oficina Sanitaria Panamericana 112:223-243, 1992.

24. Lutz A. Reminiscências da febre amarela no Estado de São Paulo. Memórias do Instituto Oswaldo Cruz 24:127-142, 1930.

25. Marchoux E, Salimbeni; Simond. A febre amarela. Relatório da Missão Francesa. O Brasil-Medico 17:473-496, 1903.

26. Marques MEA Apontamentos históricos, geográficos, biográficos, estatísticos e noticiosos da Província de São Paulo. Livraria Martins, Rio de Janeiro, Vol. 2, 1876.

27. Miranda JP. Ribeirão Preto: de ontem e de hoje. Edição comemorativa do $115^{\prime \prime}$ aniversário da Cidade, Ribeirão Preto, 1971.

28. Oliveira FP. Elementos para a história de São Simão. 1* edição,São Simão, 1975.

29. Paz C, Goes J, Neves AP. Verificação dos estudos experimentaes do Dr. Freire sobre a febre amarela. O Brazil-Medico 12:71-81, 1898.

30. Piza T. Extinção da febre amarella no norte. Discurso proferido na Sociedade de Medicina e Cirurgia de São Paulo em 1 de agosto de 1923 . O Brazil-Medico $27: 193-197,1923$.

31. Prates PC. A febre amarela. In: Ribeirão Preto de outróra. $4^{a}$ edição, Bandeirante, Ribeirão Preto, p.49-50, 1975.

32. Reed W. Recent researches concerning the etiology, propagation, and prevention of yellow fever, by the United States Army Comission. The Journal of Hygiene 2:102-1 19, 1902. 